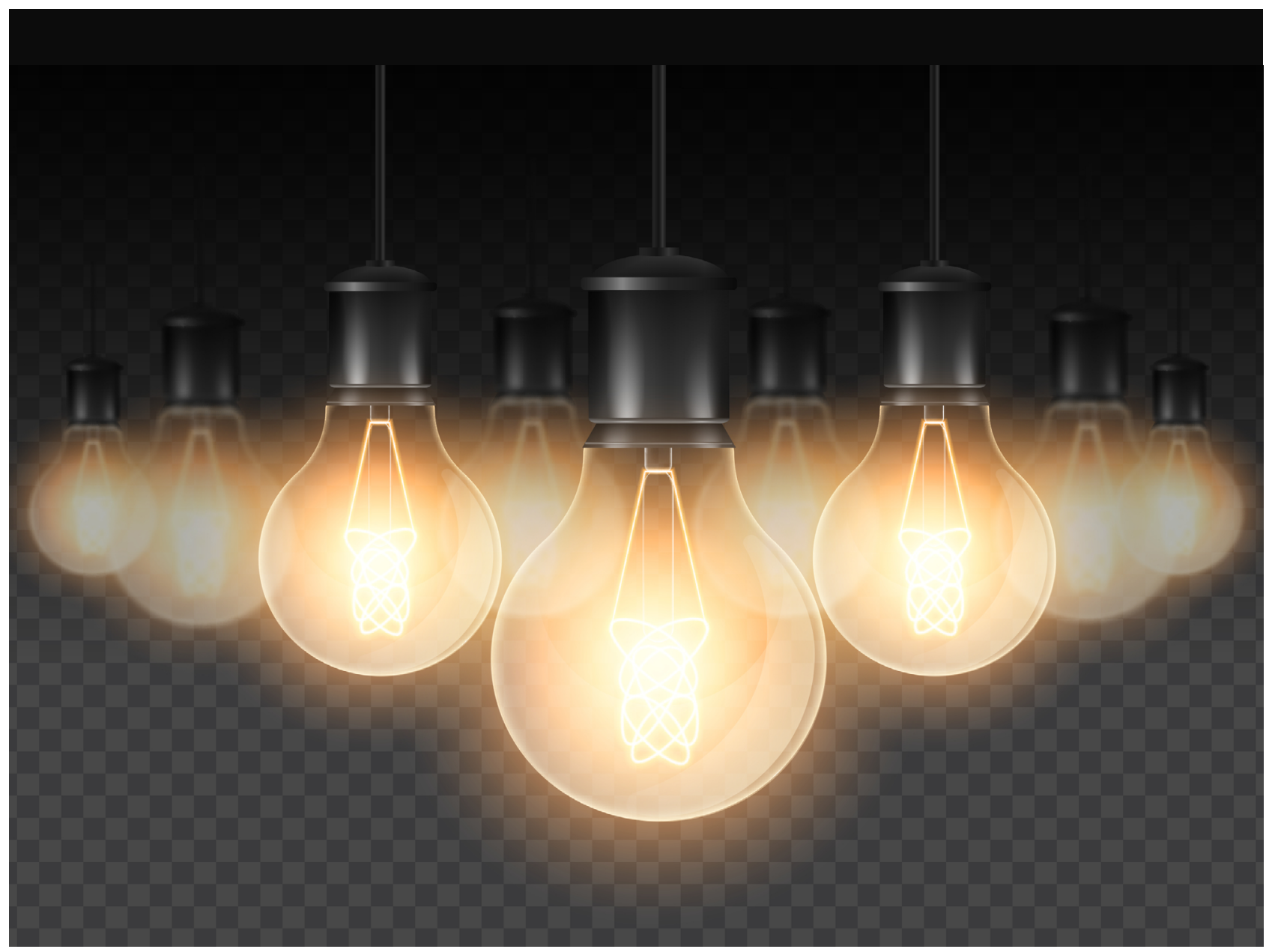

\title{
TODOS PELA INOVAÇÃO
}

SISTEMAS HORIZONTAIS COMO O DA BRASILATA E DA TUBEX MOSTRAM O POTENCIAL DE INOVAR COM A COLABORAÇÃO DO CORPO INTEIRO DE FUNCIONÁRIOS.

\section{POR ANTONIO CARLOS TEIXEIRA ALVARES}

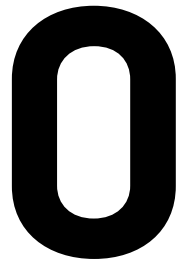

s empregados são importante fonte de ideias para inovação. No fim do século 19 , foram criados os chamados sistemas de sugestões, com a finalidade de captar essas ideias. Durante boa parte do século 20, esses sistemas obtiveram grande sucesso nos Estados Unidos, mas foi no Japão, a partir de 1950, que se popularizaram de forma extraordinária. $\mathrm{O}$ sistema norte-americano não transformava o modelo de gestão da empresa, pois bastava elaborar um sistema de captação de ideias e de premiação daquelas consideradas melhores pela alta administração - geralmente oriundas de cargos mais qualificados. Já o japonês foi uma 
mudança de paradigma, pois considerava que todos tinham capacidade de contribuir, que qualquer ideia era significativa e que os funcionários deveriam ser recompensados coletivamente, e não de maneira individual, pelos resultados.

Enquanto o modelo norte-americano criado pela Ford declinou ano a ano e acabou por ser descontinuado, o modelo japonês propagado pela Toyota capta atualmente milhões de ideias ao ano. Ainda assim, são raras as organizações que têm um sistema de ideias de alto desempenho. Os professores norte-americanos Alan Robinson e Dean Schroeder, estudiosos do assunto, definem sistema de alto desempenho como aqueles que captam pelo menos 12 ideias por funcionário por ano. No livro Organizações guiadas por ideias, Robinson e Schroeder analisam 32 empresas, sendo 19 nos Estados Unidos, oito na Europa, quatro na Ásia e uma no Brasil, a Brasilata.

A Brasilata é uma produtora de embalagens de aço, de capital brasileiro, com cerca de 1.000 funcionários. Apesar de pertencer a um setor maduro, tem sido considerada como uma das empresas mais inovadoras do Brasil. Seu sistema de ideias captou, de julho de 2019 a julho de 2020, mais de 58 mil ideias, ou 58 ideias por funcionário no ano. Fui diretor-superintendente e chief executive officer (CEO) da empresa por 37 anos e sou vice-presidente do Conselho de Administração há cinco. A Brasilata pratica o que chamei de inovação horizontal em minha dissertação de mestrado, apresentada na Escola de Administração de Empresas de São Paulo da Fundação Getulio Vargas (FGV EAESP), em 2018. O conceito representa um sistema de democratização da inovação, com captação de ideias de todos os empregados (e não apenas os de Pesquisa e Desenvolvimento ou de Marketing). Na dissertação, descobri que o modelo horizontal favorece tanto inovações incrementais como radicais. No caso da Brasilata, primeiramente apareceram, em grande quantidade, inovações incrementais, o que propiciou, em uma fase seguinte, que surgissem inovações radicais.

Em pesquisa com outras empresas brasileiras de setores maduros com sistemas que geram ao menos 12 ideias por emprego ao ano, só encontrei, até o momento, a Tubex, que produz embalagens de alumínio e conta com aproximadamente 300 funcionários. Tive a oportunidade de assessorá-la na implantação do seu sistema, que teve início em março de 2018. O número de ideias foi crescendo continuamente e atingiu, em julho de 2020, o índice de 13 ideias por funcionário por ano. Desde março de 2018 até julho de 2020, tinham sido captadas mais de seis mil ideias, das quais três deram resultados significativos e podem ser consideradas como inovações radicais.

\section{DESAFIOS}

Com a experiência adquirida incialmente na Brasilata e agora na Tubex, pude constatar que não é fácil implantar sistemas que captem mais de 12 ideias por funcionário por ano, por dois motivos principais. O primeiro deles é porque é complicado administrar um volumoso número de ideias oriundas de toda a organização. Segundo, pela necessidade de mudar a cultura dos gestores.

Em relação ao primeiro motivo, é preciso captar um número grande de ideias dos empregados, dar respostas aos autores e, se a ideia for aprovada, controlar a sua execução. A quantidade de ideias geradas e a porcentagem de ideias implementadas são critérios importantes de desempenho. Assim, o sistema deve ser bem estruturado e integrado com o sistema de gestão global da empresa.

Felizmente, a capacidade computacional é capaz de permitir, hoje em dia, uma boa gestão (não foi sempre assim). A experiência que adquirimos por mais de três décadas na Brasilata nos viabilizou a construção de um sistema de tecnologia da informação (TI) baseado em potente banco de dados, que possibilita a realização de todo o acompanhamento. O empregado deposita a ideia no sistema, a chefia imediata a analisa, e o controle é automático. Cada ideia tem prazo de sete dias para ser analisada. Ao final desse prazo, o autor recebe um retorno, tenha a ideia sido aprovada ou não. Se aprovada, deve ser executada em até 45 dias. Em passado recente, a comunicação por e-mails era prioritária, entretanto, na última versão do sistema, foi desenhado um aplicativo para que as ideias possam ser dadas e controladas pelo celular.

Em relação ao segundo motivo, o problema cultural, os desafios são mais complexos. A gestão do sistema é descentralizada. As ideias devem ser recebidas e analisadas pelo chefe imediato do autor da ideia, com a supervisão, normalmente, de Recursos Humanos. Ocorre que o sistema de gestão tradicional, baseado em comando e controle, faz com que os gestores, sobretudo dos níveis médio e baixo, acreditem inexistir valor suficiente nas ideias do pessoal de chão de fábrica que justifique o esforço de buscá-las. Além disso, faz com que acreditem que eles, como gestores, deveriam ter a exclusividade de dar ideias.

Preconceito semelhante aconteceu na década de 1970, quando os gestores de qualidade de corporações dos Estados Unidos tentaram implementar as técnicas japonesas. Eles não admitiam, a princípio, que o controle de qualidade deveria ser realizado pelos operadores de chão de fábrica, chegando até mesmo a interromper quando necessário a linha de produção. 


\section{MAS, AFINAL, O QUE VEM A SER INOVAÇÃO?}

A $3 \mathrm{M}$ define inovação como novas ideias que, implementadas, produzem resultados. Esse entendimento foi adotado pelo Fórum de Inovação da FGV EAESP, que the deu o formato de uma equação:

Inovação = ideia + implementação + resultado

Um dos critérios para classificar a inovação se baseia no resultado: inovações radicais e inovações incrementais. As radicais apresentam resultados excepcionais que mudam a base de competição da empresa; e as incrementais, pequenos resultados, mas conferem eficiência à empresa no curto prazo, reduzindo custos e melhorando as condições de trabalho.

No passado, alguns autores renomados criticaram as inovações incrementais com base na suposição de que elas atuariam contra as inovações radicais. "O incrementalismo é o pior inimigo da inovação" foi uma frase de Nicholas Negroponte repetida por Tom Peters na página 26 do seu conhecido livro 0 círculo da inovação. 0 argumento era que a preocupação com a eficiência operacional retiraria o foco da conquista de novos mercados com produtos inovadores.

É fato que as inovações radicais e as incrementais demandam recursos diferentes, porém não há antagonismo. Pelo contrário, a cultura para desenvolver tanto inovações incrementais quanto radicais é basicamente a mesma. A correlação negativa entre as inovações incrementais e as radicais foi contestada a partir da década de 2000. A literatura denominou como organizações ambidestras aquelas que conseguem realizar simultânea e sistematicamente inovações incrementais e radicais.

Para a implantação da filosofia de inovação horizontal, é fundamental que a direção da empresa, especialmente o CEO, acredite no sistema. Enquanto a resposta e execução rápida são objeto do $\mathrm{TI}$, o apoio ao modelo depende da alta administração, que deve, por exemplo, estar diretamente envolvida na entrega de premiações simbólicas aos autores das melhores ideias e aos chefes com maior número de ideias por funcionário.

Nos casos da Brasilata e Tubex, foram muito importantes a análise e a divulgação dos resultados de cada gestor em relação ao número de ideias captadas dos seus subordinados. Expor o desempenho de todos é de especial valor, uma vez que nenhum supervisor gosta de ficar nas últimas posições.

\section{CONCLUSÃO}

Para o bom funcionamento de um sistema de ideias de alto desempenho, é fundamental que ele esteja baseado na estratégia de tornar a empresa integralmente inovadora. A inovação, assim como a qualidade, deve ser de responsabilidade de todos. Os chefes precisam de alguma maneira ser valorizados pelo número de ideias de seus empregados diretos. A experiência indica que, quando as chefias do chão de fábrica compram o sistema, as ideias surgem de forma copiosa.
A implantação da inovação horizontal implica uma mudança significativa na cultura da organização, porém toda mudança organizacional consiste em um grande desafio, pois normalmente é arriscada e multifacetada. A vontade da alta gestão de adotar o sistema é chave, mas tanto ou mais importante é o convencimento do pessoal que ocupa a média e baixa gerência.

Inovação não é apenas uma questão de especialistas. A cultura interna da empresa pode conduzir à captação de inovações (inclusive radicais) por meio de todos os funcionários.

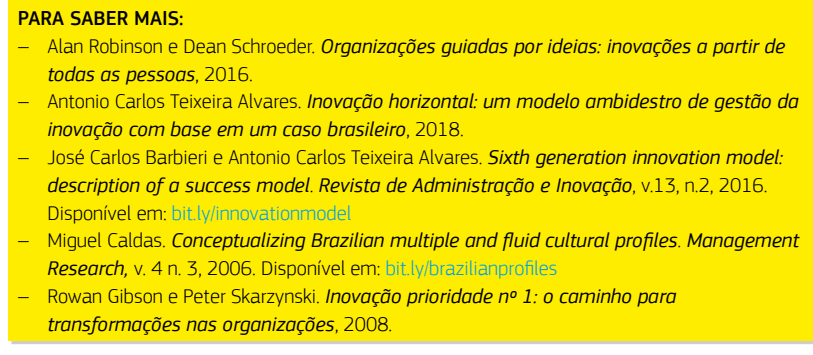

ANTONIO CARLOS TEIXEIRA ALVARES > Doutorando pelo Doctorate of Business Administration (DBA) da FGV EAESP e vice-presidente do Conselho de Administração da Brasilata > antonio.teixeira@fgv.br 